\title{
De novo Generation of an Axially Vascularized Processed Bovine Cancellous-Bone Substitute in the Sheep Arteriovenous-Loop Model
}

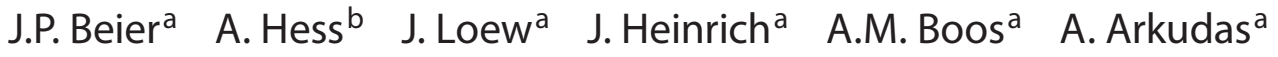 \\ E. Polykandriotis ${ }^{\mathrm{a}} \quad$ O. Bleiziffer ${ }^{\mathrm{a}} \quad$ R.E. Horch ${ }^{\mathrm{a}} \quad$ U. Kneser ${ }^{\mathrm{a}}$ \\ ${ }^{a}$ Department of Plastic and Hand Surgery, University Hospital of Erlangen, and ${ }^{\mathrm{b}}$ Institute of Pharmacology and \\ Toxicology, University of Erlangen-Nürnberg, Erlangen, Germany
}

\section{Key Words}

Reconstructive surgery $\cdot$ Bone substitute $\cdot$ Large-animal model $\cdot$ Processed bovine cancellous bone

\begin{abstract}
Background/Aims: The aim of this study was to generate an axially vascularized bone substitute. The arteriovenous (AV)loop approach in a large-animal model was applied in order to induce axial vascularization in a clinically approved processed bovine cancellous bone (PBCB) matrix of significant volume with primary mechanical stability and to assess the course of increasing axial vascularization. Methods: $\mathrm{PBCB}$ constructs were implanted into 13 merino sheep together with a microsurgically created AV loop in an isolation chamber. The vascularization process was monitored by sequential magnetic resonance imaging (MRI) scans. Explants were subjected to micro-computed tomography (micro-CT) analysis, histomorphometry and immunohistochemistry for CD31 and CD45. Results: Increasing axial vascularization in PBCB constructs was quantified by histomorphometry and visualized by micro-CT scans. Intravital sequential MRI scans demonstrated a significant progressive increase in perfused volume within the matrices. Immunohistochemistry confirmed endothelial lining of newly formed vessels. Conclu-
\end{abstract}

sion: This study demonstrates successful axial vascularization of a clinically approved, mechanically stable bone substitute with a significant volume by a microsurgical AV loop in a large-animal model. Thus microsurgical transplantation of a tissue-engineered, axially vascularized and mechanically stable bone substitute with clinically relevant dimensions may become clinically feasible in the future.

Copyright $\odot 2011$ S. Karger AG, Basel

\section{Introduction}

Reconstruction of extensive bone defects poses a major challenge to plastic and reconstructive surgeons. Despite the development of numerous biological and synthetic bone substitutes, vascularized and nonvascularized [1] autologous bone grafts remain the gold standard for osteogenic bone replacement. Given the shortcomings and complications of free autologous bone grafting, i.e. fibula, scapula or iliac crest, engineering of axially vascularized bone constructs represents a promising approach to overcome these problems. Processed bovine cancellous bone (PBCB) matrices have been successfully used for reconstruction of human bone defects [2]. Culture of osteogenic cells within $\mathrm{PBCB}$ matrices, production of calcified 
extracellular matrix and nonvascularized implantation into a small-animal model had been performed in previous studies by our group. In contrast to random vascularization of bone substitutes as e.g. in dorsal skinfold chambers [3], we then aimed for axially vascularized, thus transplantable, neobone generation. We therefore established the axial vascularization of $\mathrm{PBCB}$ matrices in an AV-loop rat model and achieved a significantly improved survival rate of implanted cells based on axial prevascularization of such a porous hard matrix $[4,5]$. These promising results led to the development of a new largeanimal model in order to pave the way towards clinical application: the sheep AV-loop model [6]. In contrast to previous studies, based on a granular, purely anorganic matrix [7], the aim of the present study was to employ a primarily stable biological hard matrix that should become axially vascularized in the sheep AV-loop model. By using clinically applicable imaging tools (MRI scans), the course of progressive vascularization was evaluated and followed by endpoint analysis including micro-CT scanning, histomorphometry and immunohistochemistry.

\section{Animals and Methods}

\section{Sheep AV-Loop Model}

Regulations for care and use of laboratory animals were observed at all times. All experiments were approved by the Animal Care Committee of the University of Erlangen and the regional government. Housing, anesthesia and postoperative management were performed as described previously [7]. The sheep received orotracheal intubation with controlled intermittent positive-pressure ventilation. Peri- and postoperatively, $4 \mathrm{mg} / \mathrm{kg}$ carprofen (Pfizer, Karlsruhe, Germany), $1 \mathrm{mg} / \mathrm{kg}$ cefquinome (Intervet, Unterschleissheim, Germany), and 2,500 IU of lowmolecular-weight heparin were administered until the 3 rd postoperative day.

All operations were performed by the same microsurgeon on a total number of 13 female merino land sheep, each weighing 24-26 kg, as described previously [7]: briefly, an AV loop was generated by a microanastomosis between the greater saphenous artery and vein. The AV loop was placed within a custom-made sterile isolation chamber. A $15-\mathrm{cm}^{3}$ block of PBCB (Tutobone ${ }^{\circledR}$ ) with a circular groove milled into the block (custom made by $\mathrm{Tu}$ togen Medical GmbH, Neunkirchen, Germany) was put inside the chamber. The AV loop was then placed around the block and into the groove (fig. 1a, b). A closed suction drain was inserted and the wound closed.

\section{Intravital MRI of AV-Loop Constructs}

Intravital MRI analysis (Siemens Vision plus 1.5 T MRI Scanner; Siemens AG, Erlangen, Germany) was performed at different postoperative time points $(1,3$ and 6 weeks or 1, 6 and 12 weeks) as described previously [7]. Five milliliters of gadofos- veset trisodium contrast agent (Vasovist ${ }^{\circledR}$; Epix Pharmaceuticals Inc., Israel) were injected intravenously. Voxels representing newly grown vessels were identified based on signal enhancement of the contrast agent within these vessels. Consequently, a $\mathrm{T}_{1}$-weighted $3 \mathrm{D}$ dataset was scanned using a 3D FLASH (TR: 12 ms, TE: $5 \mathrm{~ms}$, Flip angle $30^{\circ}$, ACQ 2 ) covering a field of view of $116 \mathrm{~mm} \times 200 \mathrm{~mm} \times 200 \mathrm{~mm}$ with a matrix size of $64 \mathrm{~mm} \times$ $256 \mathrm{~mm} \times 256 \mathrm{~mm}$.

For evaluation of MRI data, in particular the relative volume of perfused $\mathrm{PBCB}$ matrix, data analysis was performed as described previously [7]. The program MagnAn $\left({ }^{\circ}\right.$ BioCom GbR, Uttenreuth, Germany) based on IDL ( ${ }^{\circledR}$ ITT Visual Information Solution, Boulder, Colo., USA) was used. All voxels above a certain threshold were segmented and taken as a correlate of increased vascularization caused by the increased intravasal contrast agent concentration of all vessels inside the voxel. First, the isolation chamber including the pedicle was automatically segmented and used as a mask which was registered with the original dataset cutting out only voxels within the chamber. The threshold for segmentation of the voxels containing contrast agent was determined as the mean gray value plus one standard deviation of all voxels inside the chamber. The threshold for each animal was always determined at the first measurements and used for the following scans. The volume of (neo)vascularized tissue was determined as the number of voxels above the given threshold. Visualization of the image-processing results was performed in Amira ${ }^{\circledR}$ (Mercury Inc., Chelmsfort, Mass., USA) by displaying gray values of the inside of the chamber as a maximum-intensity projection onto the 3 surfaces. Within Amira, using a marching cube algorithm, an (iso)surface of the voxel above the corresponding segmentation threshold was generated, measured and displayed.

The quantitative data for vascularization volume and the corresponding surface were determined per animal and measuring time. Afterwards, the data were pooled across animals for 1-6 and 12 weeks. The significance of differences between values of 1-6 weeks versus 12 weeks was assessed applying paired Student's t tests

\section{Microfil ${ }^{\circledR}$ Injection and Micro-CT}

Postmortem imaging was performed at 6 and 12 weeks after surgery as described previously [7]. The animals received 5,000 IU heparin intravenously, then the AV-loop constructs were explanted and the pedicle artery was flushed with $60 \mathrm{ml}$ of normal saline with heparin $(5,000 \mathrm{IU} / \mathrm{ml})$ followed by perfusion with 20 ml yellow Microfil (MV-122) containing 5\% of MV curing agent (both from Flowtech, Mass., USA). Finally, both vessel stumps were ligated and the constructs were cooled at $4^{\circ} \mathrm{C}$ for $24 \mathrm{~h}$ and subsequently put into $3.5 \%$ formalin. Following 8 weeks of decalcification in EDTA solution, the explants were subjected to microCT scans using a Tomoscope 30s scanner (VAMP GmbH, Erlangen, Germany; scanning parameters: tube voltage $40 \mathrm{kV}, 40 \mu \mathrm{m}$ voxel size, 3 min scan time, $150 \mathrm{mGy}$ radiation dose). Using a marching cube algorithm within Amira, an (iso)surface of the vessel construct was generated and visualized.

Histological Analysis of Constructs

Histological analysis was performed as described previously [7]. All specimens were stained with $\mathrm{HE}$ with regions/specimen (see below) for quantitative assessment and from all specimens a 

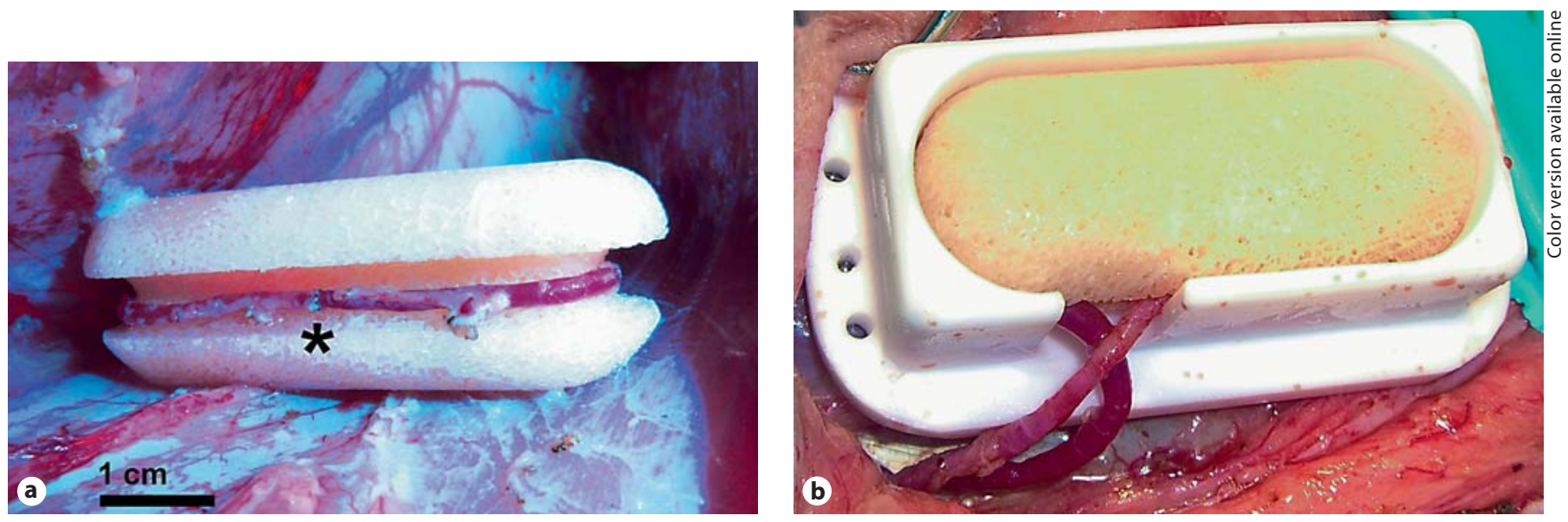

Fig. 1. a Intraoperative view of the sheep's medial thigh with a microsurgically created AV loop (asterisk = anastomosis between saphenous artery and vein) placed into the circumferential groove of a custom-made PBCB block (volume $=15 \mathrm{~cm}^{3}$ ). $\mathbf{b}$ Intraoperative view of the sheep's medial thigh with the PBCB block and the AV loop embedded in a custom-made Teflon isolation chamber, with the pedicle vessels emerging through an opening in the side wall of the chamber.

single slide was prepared for CD31/CD45 immunohistochemistry staining (qualitative assessment). Briefly, specimens were fixed in formalin, decalcified in EDTA solution, dehydrated in graded ethanol, and embedded in paraffin. Five-micrometer cross-sections were obtained from 3 standardized planes (1 central, 2 peripheral) and HE staining was performed as usual. Microphotographs (Leica Microsystems, Wetzlar, Germany) were analyzed based on 24 defined standardized regions of interest on each section at $100 \times$ magnification. Standardized regions were defined as arterial, venous, periphery of the artery, periphery of the vein and center of the construct (fig. 2). Images of 24 regions of interest were evaluated by two independent and blinded observers. The images were rendered bimodal (standardized threshold) with vessel lumina filled with Microfil solution which made them appear black (WinQ; Leica Microsystems, Bensheim, Germany). Vascular density was calculated for each group and each time. Results are given as means \pm standard deviation. Statistical analysis was performed using a two-tailed unpaired Student's t test (after confirmation of normal distribution by a Kolmogorov-Smirnov test). The critical level of statistical significance was set at $\mathrm{p}<0.05$.

\section{Immunohistochemistry}

After formalin fixation, decalcification in EDTA solution, dehydration in a graded ethanol series and paraffin embedding, the sections were incubated with Tris-buffered saline-Tween 20 and peroxidase block. Ten-percent goat serum (PromoCell GmbH, Heidelberg, Germany) was used for blocking. Incubation with the monoclonal primary antibody mouse anti-ovine CD31/PECAM-1 (MorphoSys UK Ltd., Kidlington, UK at 1:100) and secondary anti-mouse immunoglobulin-horseradish peroxidase (HRP) antibody/CSAII-System (Dako Cytomation, Carpinteria, Calif., USA), was followed by counterstaining with 4',6-diamidino-2phenylindole (Applied Science/Roche, Indianapolis, Ind., USA; 1:1,000). CD45 (leukocyte common antigen) marker (monoclonal

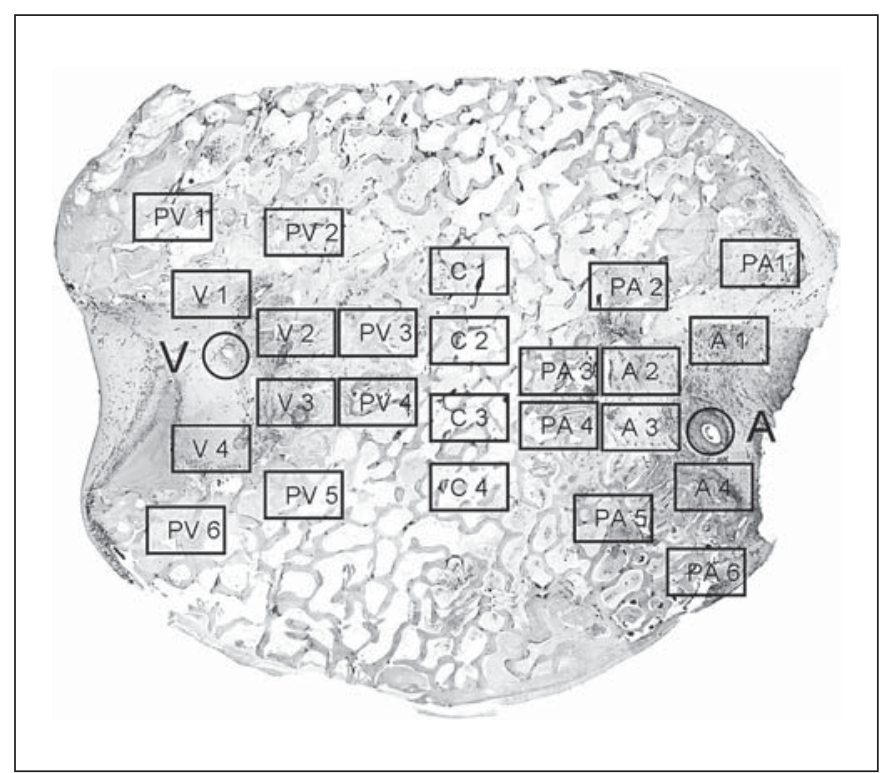

Fig. 2. Scheme of a $\mathrm{PBCB}$ specimen illustrating the 24 defined standardized regions of interest for histomorphometric analysis $(\mathrm{V}=$ venous area, $\mathrm{PV}=$ periphery of the vein, $\mathrm{A}=$ arterial area, $\mathrm{PA}=$ periphery of the artery, $\mathrm{C}=$ central part of the specimen).

mouse anti-sheep; Acris Antibodies GmbH, Herford, Germany; $1: 100$ ) was used followed by sequential 15 -min incubations with anti-mouse immunoglobulin-HRP, fluorescyl-tyramide hydrogen peroxide and anti-fluorescein-HRP of the CSAII-System with Mayer's hemalaun solution for counterstaining (Merck KGaA, Darmstadt, Germany). 

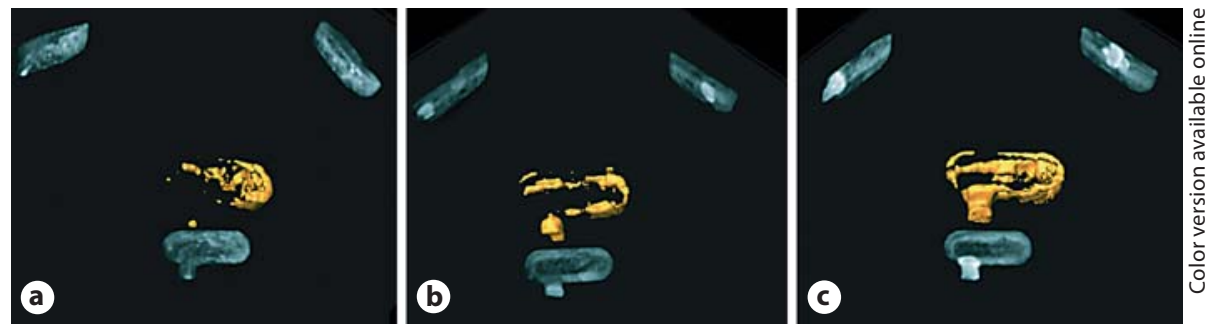

Fig. 3. Serial MRI scans of one exemplary PBCB block: black and white $=$ maximum intensity projections of the $\mathrm{PBCB}$ block showing 3 different projections, yellow $=3 \mathrm{D}$-isosurface rendering of the gadolinium-perfused part(s) of the whole construct, i.e. the axially vascularized parts of the PBCB block. The increasing vol- ume of vascularized parts within the PBCB block is demonstrated by this series of MRI scans from 1 sheep after 1 week (a), after 6 weeks (b) and after after 12 weeks (c). Colors refer to the online version only.
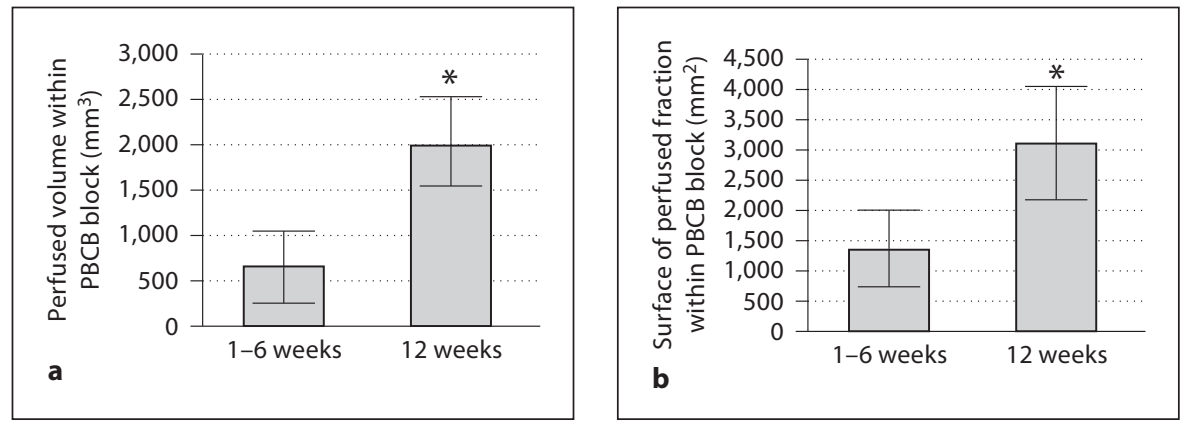

Fig. 4. a Quantitative MRI analysis of perfused volume in weeks 1-6 compared with 12 weeks shows a statistically significant $\left({ }^{*} \mathrm{p}<0.05\right.$, paired Student's t test) increase in total perfused volume within the PBCB block. $\mathbf{b}$ Quantitative MRI analysis of sur-

\section{Results}

\section{Sheep AV-Loop Model with PBCB Implantation}

Anastomoses of the saphenous artery and vein were successfully performed microsurgically in all 14 sheep using interrupted microsutures. Implantation of custommade PBCB blocks (Tutobone), into which a circumferential groove had been milled in prior to sterilization (custom made by Tutogen Medical GmbH, Neunkirchen am Brand, Germany), was facilitated by smoothly embedding the AV loop in the groove in all sheep (fig. 1a, b). The surgical procedure itself was generally well tolerated. In particular, the sacrifice of the saphenous artery and vein did not impair the circulation to the distal part of the sheep's leg. Of all implanted 14 sheep, 3 had to be excluded before completion of the study due to postoperative complications, which were not directly related to the creation of the AV loop, but to the comorbidities (pneumonia in 2 sheep and postoperative wound infection in 1 face of perfused volume in weeks 1-6 compared with 12 weeks shows a statistically significant $\left({ }^{*} p<0.05\right.$, paired Student's t test) increase in total surface of perfused volume within the PBCB block. or to the endpoint of the study of the AV loop was confirmed by imaging studies. Hence those sheep were also excluded from the study, leaving 8 sheep (4 in the 6-week group and 4 in the 12-week group) for further assessment.

\section{Intravital Imaging Analysis of Vascularization \\ by $M R I$}

The patency of AV loops was assessed by contrast-enhanced MRI over time. In 3 sheep, occlusion of the AV loop was detected prior to signs of infection, which were revealed $48 \mathrm{~h}$ later. In the other excluded sheep, signs of infection occurred during the interval between 2 scans, so MR scanning did not interfere with the decision of exclusion. Furthermore, increased perfusion of the matrix within the chamber over time could be visualized by MRI (fig. 3a-c). In all sheep, the relative amount of perfused, i.e. vascularized, volume and surface within the $\mathrm{PBCB}$ block appeared to increase progressively. A highly sig- 

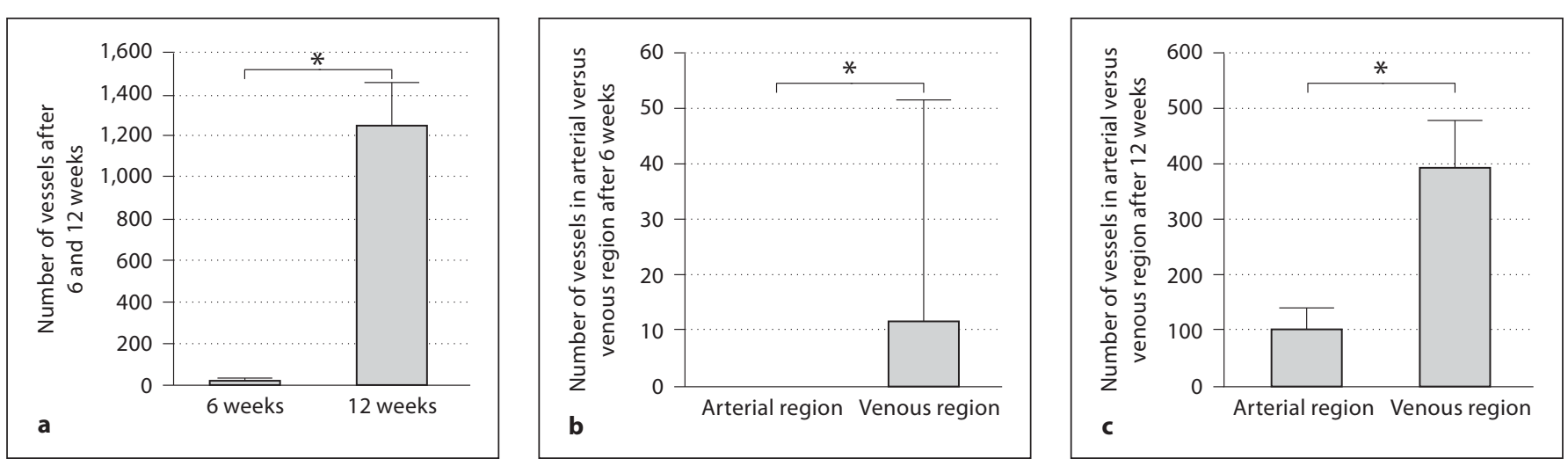

Fig. 5. a Bar diagram showing result of histomorphometric analysis: a statistically significant increase in number of counted vessels was found after 12 weeks as compared with 6 weeks (twotailed unpaired Student's t test, $\left.{ }^{*} \mathrm{p}<0.05\right)$. b Vascular outgrowth predominantly occurred from the venous section of the AV loop as estimated by a significantly $\left({ }^{*} \mathrm{p}<0.05\right)$ higher vessel count in

nificantly increased perfusion volume and surface, i.e. increased vascularization was found when comparing the total of 1-6 week group with that of the 12-week group (fig. 4a, b). The vascularized volume increased by a factor of 4 whereas the vascularized surface increased by a factor of $<3$.

\section{Endpoint Analysis: Histology and Micro-CT}

Progressive axial vascularization of the $\mathrm{PBCB}$ blocks could be detected in 3 representative HE-stained, perpendicular sections obtained from each explanted $\mathrm{PBCB}$ block (fig. 2). Identification of perfused vessels was rendered possible by filling of the lumina with Microfil solution which made them look black in histological specimens. Digital marking of these lumina with black color was successfully applied prior to bimodal image rendering for semiautomatic analysis. Sprouting of newly forming capillaries was evident in the surrounding of the main vascular axis of the AV loop. Increase in vascular density was confirmed by total vessel count 12 weeks after AVloop surgery compared with 6 weeks by a significant increase in counted vessel cross-sections (fig. 5a). Predominant vascular outgrowth occurred at the venous section of the AV loop as estimated by a significantly higher vessel count in the venous region as compared with the arterial region after 6 weeks (fig. 5b) and even more so after 12 weeks (fig. 5c). Micro-CT analysis of the explanted AVloop PBCB blocks followed by isosurface rendering for $3 \mathrm{D}$ visualization revealed progressive neovascularization derived from the AV loop: while only a very few large ves- the venous region compared with the arterial region after 6 weeks. c Histomorphometric analysis demonstrating further increase in neovascularization predominantly (statistically significant, ${ }^{*} \mathrm{p}<0.05$ ) originating from the venous part of the AV loop after 12 weeks.

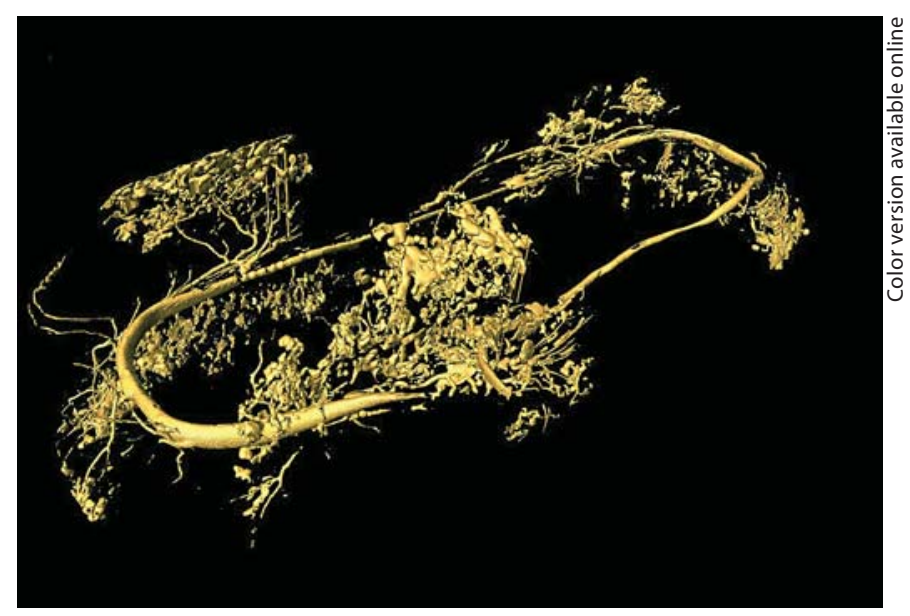

Fig. 6. 3D-isosurface reconstruction of micro-CT scan illustrating neovascularization of a PBCB block via the AV loop at 12 weeks after implantation.

sels were sprouting after 6 weeks, a dense vascular network with a variety of different vessel diameters was generated from the AV loop after 12 weeks (fig. 6). These micro-CT results could thus be positively correlated with our histomorphometric analysis. Immunohistochemistry staining for CD31 revealed positive staining for inner surface of lumina, which were filled with Microfil following perfusion through the AV-loop pedicle. Hence endothelial lining within the expected neovasculature could be evidenced (fig. 7a). However, there were no signs of 


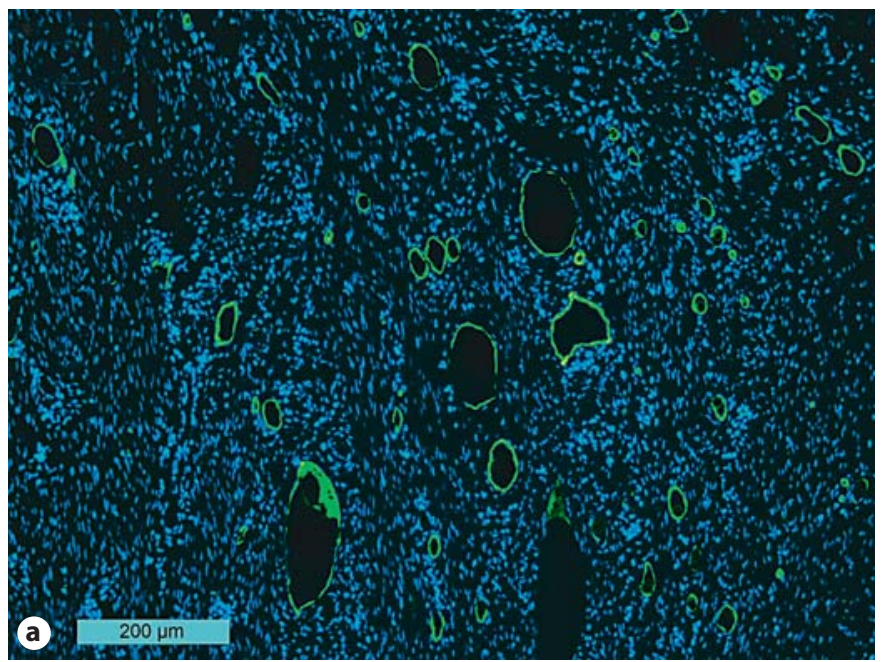

Fig. 7. a Immunohistochemical staining for CD31 revealing positive signals (green fluorescence) at the inner surface of lumina as evidence for newly formed endothelial lining (blue $=4^{\prime}, 6-\mathrm{di}$ amidino-2-phenylindole nuclear counterstaining). b Staining for leukocyte common antigen marker CD45 identifying a sig-

new bone formation, despite complete vascularization of the PBCB blocks after 12 weeks. However, we found densely vascularized connective tissue within the porous structure of the cancellous-bone constructs. While there were no signs of acute bacterial infection, a significant number of invaded leukocytes were detected by antiCD45 staining (fig. 7b).

\section{Discussion}

After previously establishing the sheep AV-loop model as the very first large-animal model for de novo generation of axially vascularized tissue substitutes using fibrin and a granular ceramic matrix $[6,7]$, the present study demonstrates its first application for creating an axially vascularized, clinically approved biological hard matrix substitute with clinically relevant dimensions. Hence transformation of the AV-loop model from an animal model to application in the patient may now become clinically feasible.

Under special conditions, such as large traumatic or cancer-related bony defects $[8,9]$, poorly vascularized, often irradiated bone defects [10] or extensive congenital bone deformities [11], the transfer of vascularized bone becomes necessary. However, vascularized bone flap transplantation techniques have certain limitations. Be-

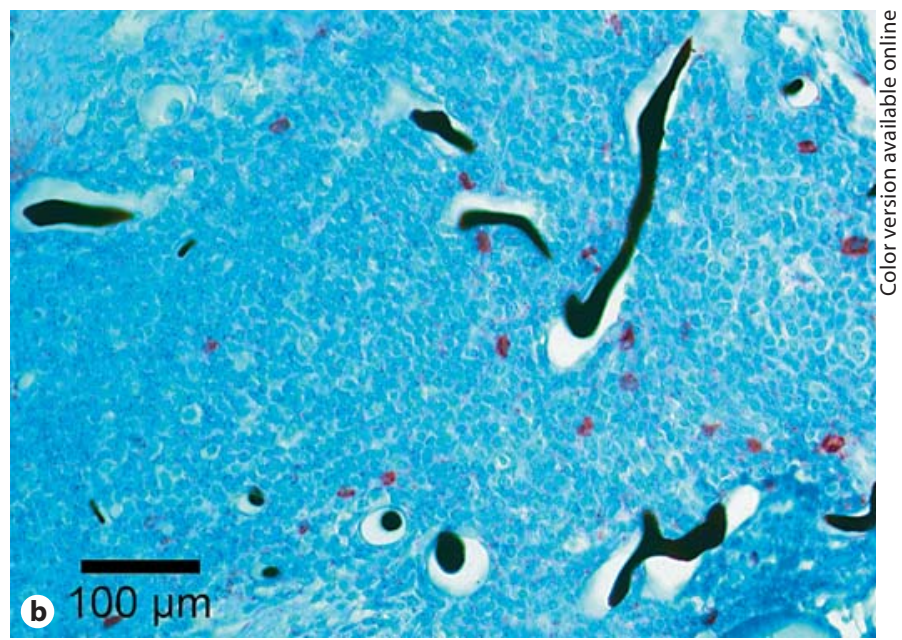

nificant number of activated, invaded leukocytes (brown staining) as a possible indicator of a foreign body reaction to the $\mathrm{PBCB}$ matrix (blue $=$ hemalaun nuclear counterstaining, black = lumina of vessels filled with Microfil after perfusion through AV-loop vessels). Colors refer to the online version only.

sides significant donor site morbidity, the spatial arrangement of the vascular pedicle within and outside the flap may limit the surgeon's options in terms of shape, geometry and placement of the flap within the defect. Bone tissue engineering aims to establish techniques for de novo bone tissue generation without significant donor site morbidity $[12,13]$. Many of these attempts have focused on the development of the optimal matrix, the use of osteogenic cells and osteogenic growth factors, both in vitro and in vivo $[12,14]$. The major problem arises upon in vivo application of most common bone tissue-engineering approaches: the neobone construct is not vascularized upon implantation, thus the vitality of cells inside the construct is limited by oxygen and nutriment supply since diffusion may only cover a maximum range of 200 $\mu \mathrm{m}$ [15]. However, the majority of tissue-engineering approaches are still based on an extrinsic, random pattern neovascularization. In this setting, the neovascular bed originates from the periphery of the construct, which should be implanted into a site of high vascularization potential. When vascularization is poor or extensive bone defects are present, free microvascular tissue is the favored approach. To overcome the hazards of free microvascular bone transplantation, de novo generation of axially vascularized and thereby transplantable bone substitutes was developed. Recognition of the potentials and characteristics of flap prelamination and prefabrication 
[16], demonstrating feasability of transferable tissue that is neovascularized by implantation of a vascular pedicle, has fathered new strategies in tissue engineering of vascularized tissue. The high potential of the AV loop as such a vascular carrier for an axial type of vascularization has been clearly demonstrated in the small-animal model and most recently even in a large-animal model $[4,6$, 17-19]. Another successful approach to generate vascularized bone tissue in a large-animal (sheep) model has recently been presented by Cheng et al. [20], who demonstrated that implantation of a poly(methyl methacrylate) chamber, filled with a morcellized-bone graft, onto the rib periosteum results in a vascularized prefabricated bone flap. Although this prefabricated flap is well vascularized and contains vital bone tissue, it lacks axial vascularization (random pattern flap) which limits clinical application. In contrast, generation of a prefabricated, axially vascularized bone flap, without the use of autogenous bone tissue (such as morcellized-bone grafts), would enhance the possibilities to transfer this neotissue to remote areas of the body. Hence the sheep AV-loop approach based on $\mathrm{PBCB}$, as presented here, could be more beneficial for possible later clinical application in bone reconstruction.

While we were previously able to induce axial vascularization in an amorphous fibrin gel or granular $H A / \beta$ TCP matrix [7], this is the first study to demonstrate axial vascularization in a mechanically stable, clinically approved bone substitute of clinically relevant size. Our PBCB matrix has been assessed in a few preclinical studies in vitro and in vivo using a small-animal model $[4,5$, 21]. Furthermore, successful application in a vertebralfusion large-animal model was pursued [22]. Application of the PBCB bone substitute in the human body has proven successful in terms of mechanical stability and osseointegration [2]. In our study, not only axial vascularization of a large PBCB construct was evident after explantation, as assessed by histomorphometry and micro-CT scans, but we also demonstrate increasing vascularization using up-to-date noninvasive, and therefore humancompatible, MRI facilities. Using appropriate image-processing algorithms and visualization techniques (e.g. maximum-intensity projections), significant perfusion increments could be demonstrated over time and the spatial distribution of neovascularized $\mathrm{PBCB}$ matrix was positively correlated with postexplantation micro-CT scans and histomorphometric findings. During the last decade, 3D-imaging tools have become more and more important with increasing clinical impact especially in perforator mapping techniques prior to perforator flap transfer. This came along with an increasing use of computed tomographic angiography, but also the associated exposure to radiation $[23,24]$. The development of MRI techniques using high-field equipment and intravascular contrast agents allows for noninvasive and radiation-free angiographic studies [25]. The diameter of newly grown vessels (less than $100 \mu \mathrm{m}$ ) is beyond the spatial resolution of current clinical MRI as well as CT techniques. Nevertheless, the use of MR perfusion imaging as an indirect marker for vascularized tissue and the application of complex 3D image-processing algorithms allows exact measurement of perfused volumes within neobone constructs. The results gained by MRI perfusion protocols and image analysis algorithms, as presented here, are encouraging in terms of radiation-free long-term vascularization monitoring and quantification in the clinical scenario. In the future, this technique could allow noninvasive determination of the optimum time point for microvascular transplantation.

One critical point for future studies will be the development of newly forming bone tissue in such an axially vascularized construct. The finding of leukocyte invasion and formation of giant cells in our constructs (CD45 immunostaining, fig. 7b) illustrates the fact that fibrous tissue and foreign body reaction may be observed instead of bone formation. Still, according to other studies [2, 22, 26], neobone formation would still be expected in this matrix upon (orthotopic) transplantation into a given bone defect followed by mechanical stimulation [27], or, as in our setting, upon implantation of osteogenic cells and/or osteogenic growth factors [28].

In summary, the sheep AV loop enables induction of axial vascularization within a clinically approved, mechanically stable PBCB bone substitute of clinically relevant size. Thus microvascular transplantation of an axially vascularized bone construct may become feasible in the future. Sequential MRI with perfusion analysis is an excellent noninvasive tool to assess the progress of vascularization, local vascularization patterns and the ideal time point for microvascular transplantation. Induction of neobone formation within the axially vascularized $\mathrm{PBCB}$ matrix will be the next step towards clinical application.

\section{Acknowledgments}

The authors would like to thank S. Fleischer, K. Schubert and I. Arnold for their technical assistance. The authors would also like to thank L. Budinsky for excellent technical work on the MRI. 
The authors thank Prof. Greil and Mr. Reinhard for producing the Teflon chambers. This work contains parts of J.L.'s and J.H.'s doctoral theses. This study was funded by the 'ELAN Fonds für Forschung und Lehre' of the University of Erlangen, Tutogen Medical GmbH, Neunkirchen am Brand, Germany, and the 'Xue Hong and Hans Georg Geis Foundation'.

\section{Disclosure Statement}

Tutobone blocks were provided by Tutogen Medical GmbH, Neunkirchen am Brand, Germany. The authors disclose no other sponsorship or funding arrangements relating to the research presented in this study. The authors disclose no conflicts of interest.

\section{References}

1 Klein MO, Grotz KA, Walter C, Wegener J, Wagner W, Al-Nawas B: Functional rehabilitation of mandibular continuity defects using autologous bone and dental implants prognostic value of bone origin, radiation therapy and implant dimensions. Eur Surg Res 2009;43:269-275.

2 Meyer S, Floerkemeier T, Windhagen $\mathrm{H}$ : Histological osseointegration of Tutobone: First results in human. Arch Orthop Trauma Surg 2008;128:539-544.

3 Lindhorst D, Tavassol F, von See C, Schumann P, Laschke MW, Harder Y, Bormann KH, Essig H, Kokemuller H, Kampmann A, Voss A, Mulhaupt R, Menger MD, Gellrich NC, Rucker M: Effects of VEGF loading on scaffold-confined vascularization. J Biomed Mater Res A 2010;95:783-792.

4 Kneser U, Polykandriotis E, Ohnolz J, Heidner K, Grabinger L, Euler S, Amann KU, Hess A, Brune K, Greil P, Sturzl M, Horch RE: Engineering of vascularized transplantable bone tissues: induction of axial vascularization in an osteoconductive matrix using an arteriovenous loop. Tissue Eng 2006; 12:1721-1731.

5 Arkudas A, Beier JP, Heidner K, Tjiawi J, Polykandriotis E, Srour S, Sturzl M, Horch RE, Kneser U: Axial prevascularization of porous matrices using an arteriovenous loop promotes survival and differentiation of transplanted autologous osteoblasts. Tissue Eng 2007;13:1549-1560.

6 Beier JP, Horch RE, Arkudas A, Polykandriotis E, Bleiziffer O, Adamek E, Hess A, Kneser U: De novo generation of axially vascularized tissue in a large animal model. Microsurgery 2009;29:42-51.

7 Beier JP, Horch RE, Hess A, Arkudas A, Heinrich J, Loew J, Gulle H, Polykandriotis E, Bleiziffer O, Kneser U: Axial vascularization of a large volume calcium phosphate ceramic bone substitute in the sheep AV loop model. J Tissue Eng Regen Med 2010;4:216223.

8 Yazar S, Lin CH, Wei FC: One-stage reconstruction of composite bone and soft-tissue defects in traumatic lower extremities. Plast Reconstr Surg 2004;114:1457-1466.
9 Chang DW, Weber KL: Use of a vascularized fibula bone flap and intercalary allograft for diaphyseal reconstruction after resection of primary extremity bone sarcomas. Plast Reconstr Surg 2005;116:1918-1925.

10 Hanasono MM, Weinstock YE, Yu P: Reconstruction of extensive head and neck defects with multiple simultaneous free flaps. Plast Reconstr Surg 2008;122:1739-1746.

11 Guo L, Ferraro NF, Padwa BL, Kaban LB, Upton J: Vascularized fibular graft for pediatric mandibular reconstruction. Plast Reconstr Surg 2008;121:2095-2105.

12 Hutmacher DW, Horch RE, Loessner D, Rizzi S, Sieh S, Reichert JC, Clements JA, Beier JP, Arkudas A, Bleiziffer O, Kneser U: Translating tissue engineering technology platforms into cancer research. J Cell Mol Med 2009;13:1417-1427.

13 Kneser U, Schaefer DJ, Polykandriotis E, Horch RE: Tissue engineering of bone: the reconstructive surgeon's point of view. J Cell Mol Med 2006;10:7-19.

14 Bleiziffer O, Eriksson E, Yao F, Horch RE, Kneser U: Gene transfer strategies in tissue engineering. J Cell Mol Med 2007;11:206223.

15 Goldstein AS, Juarez TM, Helmke CD, Gustin MC, Mikos AG: Effect of convection on osteoblastic cell growth and function in biodegradable polymer foam scaffolds. Biomaterials 2001;22:1279-1288.

16 Pribaz JJ, Fine N, Orgill DP: Flap prefabrication in the head and neck: a 10-year experience. Plast Reconstr Surg 1999;103:808-820.

17 Beier JP, Horch RE, Hess A, Arkudas A, Heinrich J, Loew J, Gulle H, Polykandriotis E, Bleiziffer O, Kneser U: Axial vascularization of a large volume calcium phosphate ceramic bone substitute in the sheep AV loop model. J Tissue Eng Regen Med, in press

18 Polykandriotis E, Tjiawi J, Euler S, Arkudas A, Hess A, Brune K, Greil P, Lametschwandtner A, Horch RE, Kneser U: The venous graft as an effector of early angiogenesis in a fibrin matrix. Microvasc Res 2007;75:25-33.

19 Polykandriotis E, Horch RE, Arkudas A, Labanaris A, Brune K, Greil P, Bach AD, Kopp J, Hess A, Kneser U: Intrinsic versus extrinsic vascularization in tissue engineering. Adv Exp Med Biol 2006;585:311-326.
20 Cheng MH, Brey EM, Allori AC, Gassman A, Chang DW, Patrick CW Jr, Miller MJ: Periosteum-guided prefabrication of vascularized bone of clinical shape and volume. Plast Reconstr Surg 2009;124:787-795.

21 Kneser U, Stangenberg L, Ohnolz J, Buettner O, Stern-Straeter J, Mobest D, Horch RE, Stark GB, Schaefer DJ: Evaluation of processed bovine cancellous bone matrix seeded with syngenic osteoblasts in a critical size calvarial defect rat model. J Cell Mol Med 2006;10:695-707.

22 Kubosch D, Milz S, Sprecher CM, Sudkamp NP, Muller CA, Strohm PC: Effect of graft size on graft fracture rate after anterior lumbar spinal fusion in a sheep model. Injury 2010;41:768-771.

23 Rozen WM, Pan WR, Le Roux CM, Taylor GI, Ashton MW: The venous anatomy of the anterior abdominal wall: an anatomical and clinical study. Plast Reconstr Surg 2009;124: 848-853.

24 Rozen WM, Chubb D, Ashton MW: Advantages of preoperative computed tomography in deep inferior epigastric artery perforator flap breast reconstruction. Plast Reconstr Surg 2009; 124:1367-1368; author reply 1368.

25 Alonso-Burgos A, Garcia-Tutor E, Bastarrika G, Benito A, Dominguez PD, Zubieta JL: Preoperative planning of DIEP and SGAP flaps: preliminary experience with magnetic resonance angiography using 3-tesla equipment and blood-pool contrast medium. J Plast Reconstr Aesthet Surg 2009;63:298304.

26 Candrian C, Barbero A, Bonacina E, Francioli S, Hirschmann MT, Milz S, Valderrabano V, Heberer M, Martin I, Jakob M: A novel implantation technique for engineered osteo-chondral grafts. Knee Surg Sports Traumatol Arthrosc 2009;17:1377-1383.

27 Tischer T, Milz S, Weiler C, Pautke C, Hausdorf J, Schmitz C, Maier M: Dose-dependent new bone formation by extracorporeal shock wave application on the intact femur of rabbits. Eur Surg Res 2008;41:44-53.

28 Smrke D, Gubina B, Domanovic D, Rozman P: Allogeneic platelet gel with autologous cancellous bone graft for the treatment of a large bone defect. Eur Surg Res 2007;39:170174. 